\title{
ATLAS GEOGRÁFICO MUNICIPAL: CONTRIBUIÇÕES PARA A ELABORAÇÃO DE UMA PROPOSTA PEDAGÓGICA PARA O ENSINO FUNDAMENTAL NO MUNICÍPIO DE PELOTAS/RS
}

\author{
Luiza dos Anjos Lopes $^{(a)}$, Rosa Elena Noal ${ }^{\left({ }^{(b)}\right.}$ \\ (a) Graduação em Geografia, Universidade Federal de Pelotas, lupiita.lopes@gmail.com \\ (b) Departamento de Geografia/Universidade Federal de Pelotas, rosa.noal@ gmail.com
}

EIXO: GEOGRAFIA FÍSICA: CURRÍCULO, FORMAÇÃO E PRÁTICAS DE ENSINO.

\begin{abstract}
Resumo
O estudo tem como objetivo subsidiar a elaboração de uma proposta de Atlas Geográfico do Município de Pelotas/RS, adequando-o as necessidades do município, direcionado ao processo de ensino-aprendizagem da Geografia no Ensino Fundamental. Foi realizado um levantamento e análise de referências bibliográficas, bem como entrevistas com quatro professores de Geografia da rede de ensino fundamental do município, que abordam o conteúdo referente a Geografia de Pelotas. Foi verificada a existência de diferentes metodologias utilizadas na elaboração de atlas escolares. Observou-se que existe uma grande demanda pela elaboração de um atlas do município de Pelotas, principalmente que aborde os aspectos físicos, processo histórico de ocupação e socioculturais. Este fato evidencia que a elaboração da proposta do Atlas Municipal de Pelotas pode vir a permitir ao estudante acesso ao conhecimento e que ele seja atuante no meio onde ele vive.
\end{abstract}

Palavras chave: Cartografia; Ensino de Geografia; Atlas; Ensino Fundamental.

\section{Introdução}

O presente trabalho é pautado em uma forte atribuição da cartografia, determinada pelo uso dos Atlas, com suas possíveis aplicações didáticas no ensino fundamental para o município de Pelotas/RS, o qual não é possuidor deste recurso didático que pode contribuir substancialmente para o ensino de Geografia e para a compreensão do espaço local.

O atlas é um recurso didático elaborado sob a concepção de ensino que pode levar a uma melhor compreensão crítica e reflexiva acerca da realidade local, dos lugares, dos territórios, das diferentes regiões, interconectados nas redes, uma vez que reúnem e sintetizam as inúmeras informações e conhecimento sobre a realidade, isto é, são modelos conceituais sobre o mundo que contribuem significativamente para a interpretação e entendimento das relações e da organização do espaço (JUNIOR e ZUCCHIA, 2013; BATISTA e VALENTE, 2014).

Entende-se que o uso de atlas municipais torna possível de ser colocada em prática uma questão intrínseca a Geografia, que é o estudo do lugar, o qual é fundamental ao desenvolvimento de noções de identidade e 
do sentimento de pertencimento ao meio onde se vive, o que, consequentemente, faz com que as pessoas valorizem mais as localidades onde vivem (ALMEIDA, 2007).

Para Junior e Zucchi (2013), além de conter informações importantes e precisas sobre as características geográficas do município, o Atlas Municipal desperta nos usuários um sentimento de pertencimento do lugar, através dos demais conteúdos abrangidos. Desta maneira, auxilia o educando na compreensão do seu espaço, ajudando-o a construir conceitos, sistematizar seus conhecimentos e a assimilar os produtos científicos da humanidade (SOUZA e KATUTA, 2001).

Neste contexto, o trabalho foi desenvolvido com o objetivo de subsidiar a elaboração de uma proposta de Atlas Geográfico do Município de Pelotas/RS, adequando-o as necessidades do município, direcionado ao processo de ensino-aprendizagem da Geografia no Ensino Fundamental.

\section{Metodologia}

Para o desenvolvimento desta pesquisa foi realizado um levantamento e análise de referências bibliográficas que possibilitaram identificar diferentes metodologias utilizadas na elaboração de atlas escolares. Esta revisão de literaturas buscou suporte em artigos, dissertações de mestrado e teses de doutorado que abordam experiências com a temática. Destacam-se alguns autores que realizaram outros projetos de atlas escolares municipais como: Almeida (2003); Batista e Valente (2014); Faria (2015); e Martinelli (2008).

Posteriormente, para subsidiar a elaboração do projeto de Atlas Municipal de Pelotas foram realizadas entrevistas com quatro professores (A, B, C e D) de Geografia da rede de ensino fundamental do município de Pelotas, que abordam o conteúdo referente a Geografia de Pelotas. Este momento da pesquisa ocorreu com o objetivo de identificar quais conhecimentos cartográficos os alunos têm mais dificuldade e se os alunos conhecem o município, uma vez que se entende que não conhecer o local onde vive acaba comprometendo a identidade e sentimento de pertencimento do indivíduo com o espaço geográfico onde ele está inserido.

As entrevistas ocorreram de uma forma onde o professor pudesse expor sua opinião, onde se estabeleceu um diálogo enfocando conteúdos necessários para a elaboração de um atlas municipal, como: questões vinculadas ao processo histórico de ocupação, clima, características físicas, demografia, mobilidade da população, circulação de mercadorias, entre outras. 


\section{Resultados}

Foram analisados estudos que abordaram a temática dos atlas geográficos escolares, a partir de estudos de caso nos municípios de Apucarana/PR; Cambira/PR; Quevedo/RS; Rio Claro/SP; Restinga Seca/RS; e Sorocaba/SP. Os resultados obtidos a partir da análise bibliográfica possibilitaram identificar que existem diferentes metodologias utilizadas na elaboração de atlas escolares municipais. Algumas consideram na sua elaboração os saberes dos alunos; outras partem de entrevistas e/ou aplicação de questionários com professores do Ensino Fundamental; também há propostas que desenvolvem atividades colaborativas envolvendo pesquisadores, professores e alunos do Ensino Fundamental. Verificou-se que a experiência destes estudos foi positiva, considerando que tal recurso didático contribui para o processo de ensinoaprendizagem do aluno e do professor, sendo o atlas uma ferramenta de interação, possibilitando um olhar mais crítico, onde os mapas são vistos como formas de saber socialmente construídas, e não como meras imagens sem valor. O conteúdo temático se fundamenta numa lucubração básica do conhecimento geográfico: a natureza em composição com a sociedade (MARTINELLI, 2008).

De acordo com Faria (2015), para a elaboração de um atlas municipal é necessária uma equipe, pois esse processo sugere a participação da comunidade integrada à pesquisa. É partindo deste princípio que se buscou a participação dos professores, pois são estes que atuam na sala de aula e conhecem as dificuldades do aluno.

$\mathrm{Na}$ análise das entrevistas, inicialmente procurou-se questionar os professores a respeito de quais conhecimentos cartográficos os alunos têm mais dificuldade em sala de aula. Todos os professores mencionaram que os alunos possuem bastante dificuldade no que se refere à orientação e escala, proporção, entendimento básico acerca de símbolos cartográficos e das diferentes formas de representação do espaço como, croqui, planta, mapa, infográfico, e maquete. Os professores ainda destacaram que os alunos saem das séries iniciais com conhecimento mínimo acerca da realidade local e do espaço geográfico onde estão inseridos. O professor A destacou que procura retomar alguns pontos necessários, porém, sente resistência por parte de alguns educandos quando o assunto requer mais atenção e raciocínio lógico, mesmo que o tema esteja intimamente ligado à realidade da comunidade em que eles estão inseridos.

Posteriormente, os professores foram questionados acerca dos recursos didáticos no ensino de conteúdos cartográficos do município de Pelotas, onde se buscou compreender se existem uma variedade de recursos à disposição do professor, ou uma carência de recursos didáticos. Novamente as respostas foram bastante similares, onde os professores destacaram que existe uma grande carência no ensino público. De acordo com os docentes A, C e D, existe uma grande lacuna entre o que seria o básico e o que temos para utilizar 


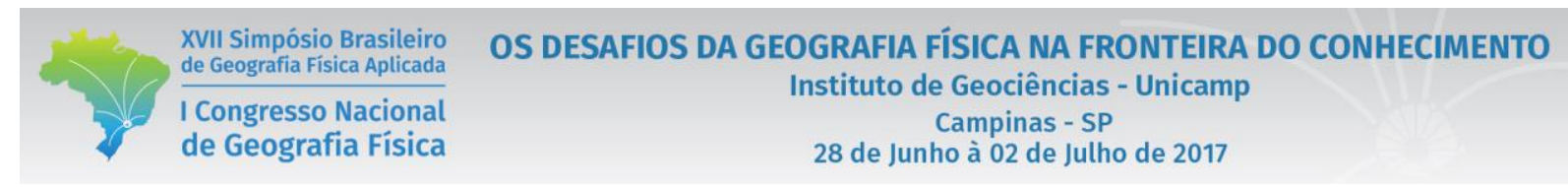

nas aulas de Geografia. Em alguns casos, os professores destacaram que possuem poucos recursos disponíveis na escola, e, portanto, buscam o uso da criatividade para tentar sanar parte dos problemas no que se refere à carência de ferramentas didáticas.

Ainda no que se refere às informações sobre o município de Pelotas, em um segundo momento das entrevistas, estabeleceu-se um diálogo com os docentes, com o objetivo de saber dos mesmos a importância que um Atlas Municipal teria para o conhecimento geográfico local dos alunos. Todos os docentes afirmaram que um Atlas do município de Pelotas seria extremamente útil para o ensinoaprendizagem dos discentes. Neste contexto, o professor B enfatizou que o indivíduo que reconhece seu espaço em uma sociedade, é capaz de enxergar a realidade com clareza e mais objetividade. De acordo com este professor, o passo inicial para esse reconhecimento do espaço seria entender o lugar onde se vive e toda sua dinámica, e o Atlas atenderia a estas exigências.

Neste contexto, Carreiro (2003) salienta que:

(...) Atlas Municipal Escolar se constitui em um material didático elaborado sob a concepção de ensino que pode levar a uma melhor compreensão crítica e reflexiva acerca da realidade local (CARREIRO, 2003).

Conforme os professores foram ressaltando a importância do Atlas, os mesmos foram questionados a respeito de quais conteúdos ou mapas temáticos eles consideram necessários e que devem constar na elaboração de um atlas municipal de Pelotas. Dos quatro professores entrevistados, os professores A e C destacaram a necessidade de trazer informações referentes aos aspectos turísticos, socioculturais, bem como questões vinculadas as característica físicas, como: bacias hidrográficas; rede hidrográfica; vegetação; e geologia. De acordo com estes dois professores, estas informações colocadas em um atlas, seria muito oportuno, uma vez que esse desconhecimento pode levar a um descontentamento de estar neste espaço geográfico.

Ainda sobre os conteúdos que devem constar na elaboração de um atlas municipal de Pelotas, os professores B e D consideraram interessante o material trazer informações das características físicas de Pelotas, e citaram alguns exemplos: desenvolvimento urbano, agropecuário, geomorfologia, pedologia, e uso do solo urbano e rural. Conforme estes professores, este fato poderia contribuir para uma maior troca de saberes entre o professor e os alunos aproximando o aprendizado escolar da realidade cotidiana vivida fora da escola.

Neste contexto, destacam-se as respostas do professor D, o qual leciona em uma escola, que muito embora pertença à zona urbana de Pelotas possui fortes características do meio rural. Esta escola fica distante aproximadamente dez quilômetros do centro da cidade, e atende cerca de 600 alunos, em sua grande 


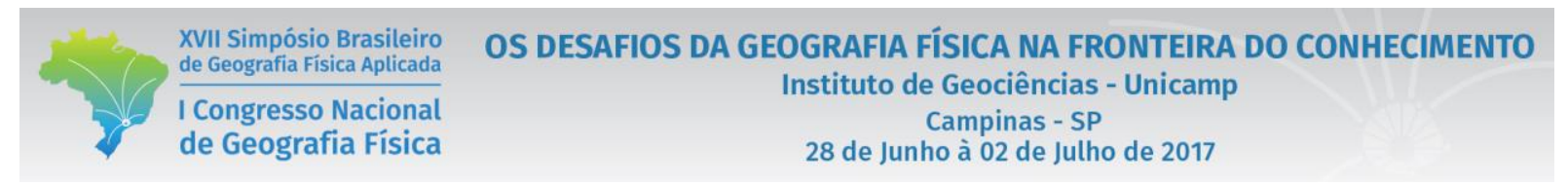

maioria residente no próprio bairro. Para o professor entrevistado, muitos dos seus alunos não têm acesso às regiões mais afastadas do seu lugar de origem, e, portanto, um atlas seria um auxílio valioso para tentar diminuir distancias entre o teórico e o prático.

\section{Considerações finais}

A partir nas interpretações realizadas, entende-se que a construção de um Atlas geográfico do Município de Pelotas/RS irá contribuir substancialmente para o ensino de Geografia e para a compreensão das transformações na organização do espaço local. Entende-se que é indispensável à compreensão do espaço geográfico, objeto de estudo da Geografia, pois permite uma melhor compreensão das características geográficas do município de Pelotas.

Com base nas entrevistas realizadas com os professores de Geografia da rede de ensino fundamental do município de Pelotas, observou-se que existe realmente uma demanda por este material didático, principalmente que aborde os aspectos físicos, processo histórico de ocupação e socioculturais do município.

A elaboração da proposta do Atlas Municipal de Pelotas pode vir a subsidiar e instigar estudantes não só da ciência geográfica, mas também estudantes de outras ciências, que certamente poderão contribuir para que o projeto de elaboração do Atlas do Município de Pelotas seja colocado em prática, a fim de permitir ao estudante acesso ao conhecimento e que ele seja atuante no meio onde ele vive.

\section{REFERÊNCIAS}

ALMEIDA, R. D. de. Cartografia Escolar. São Paulo: Contexto, 2007.

BATISTA, N. L.; VALENTE, V. Atlas Geográfico do Município de Quevedo/RS. Revista Percurso - NEMO, v. 6, n. 2, p. 121- 140, 2014.

CARREIRO, M. S. A. Um olhar geográfico sobre a construção do Atlas Municipal e Escolar de Rio Claro. Cad. Cedes, v. 23, n. 60, p. 169-178, 2003.

FARIA, M.C. A pesquisa participante na elaboração de atlas municipal escolar: a experiência do atlas de ApucaranaPR. 2015. Tese (Doutorado em Geografia), Universidade Estadual Paulista, Rio Claro.

JUNIOR, P.F.; ZUCCHI, V.P. A construção do Atlas municipal de Cambira/PR: para o ensino e a aprendizagem Geográfica do lugar. Geografia Ensino \& Pesquisa, v. 17, n.1, jan./abr. 2013. MARTINELLI, M. Um atlas geográfico escolar para o ensino-aprendizagem da realidade natural e social. Portal da Cartografia. Londrina, v.1, n.1, p.21-34, 2008

SOUZA, J.G.; KATUTA, A.M. Geografia e conhecimentos cartográficos: A cartografia no movimento de renovação da geografia brasileira e a importância do uso de mapas. São Paulo: UNESP, 2001. 